REVIEW

\title{
Lumbar osteotomy for correction of thoracolumbar kyphotic deformity in ankylosing spondylitis. A structured review of three methods of treatment
}

\author{
B J Van Royen, A De Gast
}

\begin{abstract}
Objectives-Three operative techniques have been described to correct thoracolumbar kyphotic deformity (TLKD) resulting from ankylosing spondylitis (AS) at the level of the lumbar spine: opening wedge osteotomy, polysegmental wedge osteotomies, and closing wedge osteotomy. Little knowledge exists on the indication for, and outcome of these corrective lumbar osteotomies.

Methods-A structured review of the medical literature was performed.

Results-A search of the literature revealed 856 patients reported in 41 articles published between 1945 and 1998. The mean age at time of operation was 41 years, male-female ratio 7.5 to 1 . In 451 patients an open wedge osteotomy was performed. Polysegmental wedge osteotomies were performed in 249 patients and a closing wedge osteotomy in 156 patients. Most of the studies primarily focus on the surgical technique. Technical outcome data were poorly reported. Sixteen reports, including 523 patients, met the inclusion criteria of this study, and could be analysed for technical outcome data. The average correction achieved with each surgical techniques ranged from 37 to 40 degrees. Loss of correction was mainly reported in patients treated by open wedge osteotomy and polysegmental wedge osteotomies. Neurological complications were reported in all three techniques. The perioperative mortality was $4 \%$. Pulmonary, cardiac and intestinal problems were found to be the major cause of fatal complications.
\end{abstract}

Department of Orthopaedic Surgery, Free University Hospital, De Boelelaan $11171081 \mathrm{HV}$

Amsterdam, the Netherlands

Correspondence to: Dr B J Van Royen. rection of TLKD resulting from $A$ S major surgery. The indication for these lumbar osteotomies as well as the degree of correction in the lumbar spine has not yet been established. Furthermore, there is a need for a generally accepted clinical score that encompasses accurate preoperative and postoperative assessment of the spinal deformity. The results of this review suggest that the data from the literature are not suitable for decision making with regard to surgical treatment of TLKD resulting from AS.

(Ann Rheum Dis 1999;58:399-406)

Despite adequate conservative treatment, ankylosing spondylitis (AS) may lead to a severe fixed thoracolumbar kyphotic deformity (TLKD) of the spine..$^{1-5}$ The TLKD can be so extreme that the patient cannot sit, stand, or lie in comfort. In few patients a corrective osteotomy of the spine may be considered. The aim of a spinal osteotomy is to restore both the patient's balance and the ability to see ahead to the horizon. In addition, the intervention aims to relieve compression of the abdominal viscera by the margin of the inferior rib cage, and improves diaphragmatic respiration. In AS, the spinal deformity mostly is a combination of a thoracic hyperkyphosis and flattening of the lumbar lordosis. The TLKD is best corrected by a lordosating osteotomy of the lumbar spine, as thoracic correction is strongly limited by ankylosis of the costovertebral joints. $.^{3-4} 6-11$ Furthermore, the overall correction is greatest when the intervention is performed at the lowest possible level of the lumbar spine. ${ }^{791213}$ In addition, the relative narrow thoracic spinal canal renders the mid-thoracic spinal cord more vulnerable to perioperative injury than the cauda equine in its spacious spinal canal.

Reports on lumbar osteotomies for correction of TLKD attributable to AS are limited. Most authors reported results of only few patients. $^{74-25}$ Few authors, however, have experience from more than 50 patients. ${ }^{9}{ }^{12} 26-28$

History and current options for surgical treatment

Three operative techniques have been de- scribed to correct TLKD resulting from AS at the level of the lumbar spine: opening wedge osteotomy, polysegmental wedge osteotomies, and closing wedge osteotomy.

The original technique is commonly credited to Smith-Petersen et al, who reported on anterior opening wedge osteotomies in six patients in $1945 .^{10}$ This technique ${ }^{10}$ involved two and three level osteotomies through the 
A

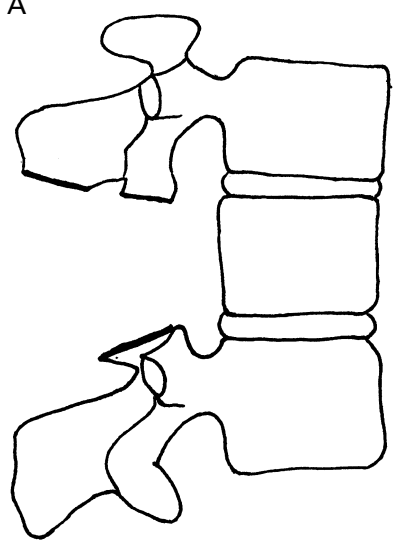

B

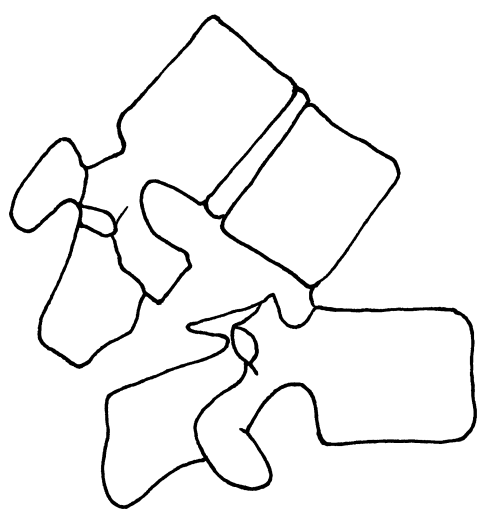

Figure 1 Diagrams of the opening wedge osteotomy (OWO). (A) Lateral view outlining the bone block to be resected. (B) Postoperative lateral view showing how correction is achieved by closure of the posterior elements, and creating an open wedge of the anterior column.

A

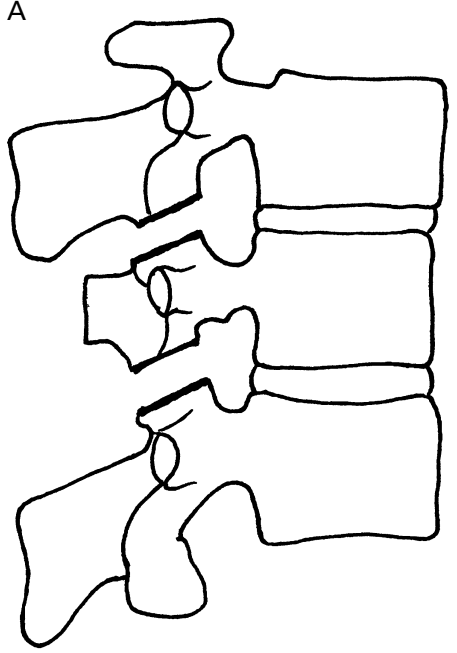

B

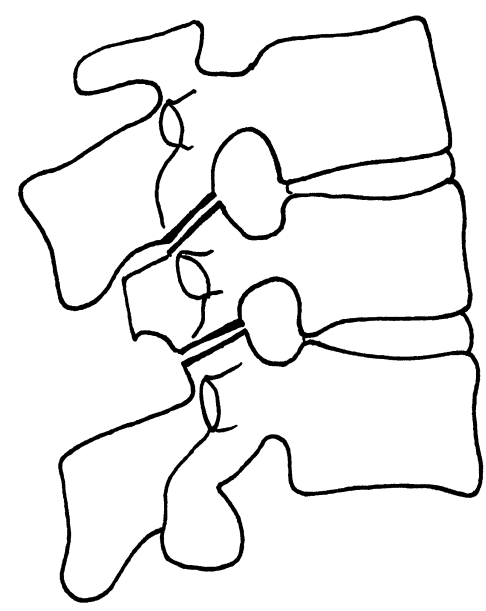

Figure 2 Diagrams of the polysegmental wedge osteotomies (PWO). (A) Lateral view outlining the bone blocks to be resected through the original facet joints in the direction of the interspinal foremen. (B) Postoperative lateral view showing how correction is achieved by closure of the posterior osteotomies.

A

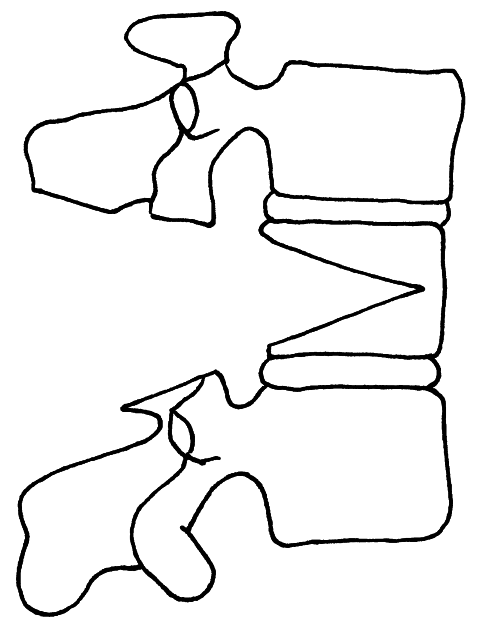

B

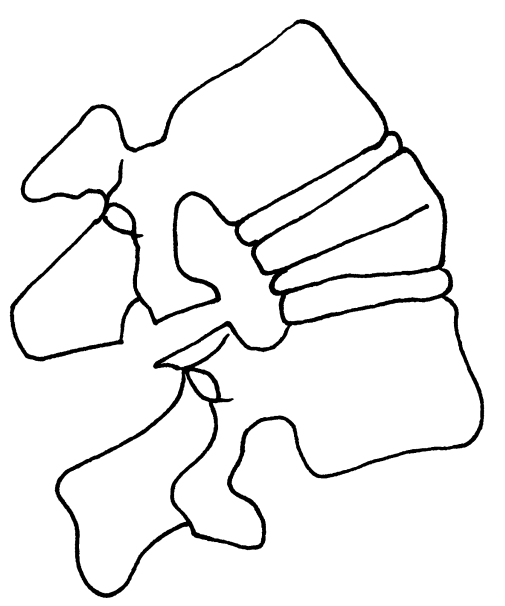

Figure 3 Diagrams of the closing wedge osteotomy (CWO). (A) Lateral view outlining the bone block to be resected. (B) Postoperative lateral view showing how correction is achieved by closure of the intravertebral osteotomy.

articular processes of L1, L2, and L3. Correction of the kyphotic deformity was achieved by forceful manual extension of the lumbar spine in an attempt to close the posterior wedge osteotomies. This manipulation caused disruption of the anterior longitudinal ligament creating an anterior monosegmental intervertebral opening wedge with elongation of the anterior column (fig 1).

In the same period, however, the Dutch orthopaedic surgeon La Chapelle ${ }^{20}$ described a two stage anterior opening wedge osteotomy for correction of TLKD in one patient. He first removed the lamina of L2 under local anaesthesia, followed two weeks later by an anterior release and resection of the intervertebral disc between L2 and L3. The anterior osteotomy was then wedged open and grafted with a bone block. Many modifications of this anterior opening wedge osteotomy have been described. ${ }^{13-6} 1112152627$ 29-39 The sharp lordotic angle and elongation of the anterior column occurring in this procedure, were assumed to be associated with serious vascular and neurological complications. ${ }^{612192426333638}$ To avoid such complications, polysegmental posterior wedge osteotomies and closing wedge posterior osteotomies of the lumbar spine were introduced.

In 1949, Wilson and Turkell ${ }^{25}$ first reported on a patient with TLKD attributable to AS treated by polysegmental lumbar posterior wedge osteotomies. Correction was achieved by multiple closing wedges of posterior lumbar osteotomies, including the interlaminar space and the original inferior and superior articular processes. This method gives a more gradual correction without rupturing of the anterior longitudinal ligament (fig 2). In the 1980s, Zielke $^{9} 40-44$ also advocated polysegmental lumbar posterior wedge osteotomies, however with the use of internal fixation. $\mathrm{He}$ and his colleagues first used Harrington rods and laminar hooks, and later transpedicular screws.

Correction of TLKD resulting from AS by a monosegmental intravertebral closing wedge posterior osteotomy of the lumbar spine was first described by Scudese in $1963^{22}$ and later by Ziwjan in $1982^{28}$ and Thomasen in $1985 .{ }^{45} \mathrm{In}$ this technique, the posterior elements of one vertebra, including the lamina, articular processes, pedicles, in combination with the posterior wedge of the vertebral body are resected. Correction is achieved by passive extension of the lumbar spine, thus closening the posterior osteotomy with an anterior hinge (fig 3). Internal fixation with wiring, metal plates or transpedicular fixation has been used to ensure immediate stability and rapid consolidation. ${ }^{13} 174546$

At present, these three different surgical techniques are in use to treat TLKD caused by AS. ${ }^{1327} 354147$ Some authors prefer polysegmental lumbar posterior wedge osteotomies or a monosegmental closing wedge posterior osteotomy because of the high complication and mortality rate associated with anterior opening wedge osteotomy. ${ }^{291316172235}$ However, this association is challenged by others. ${ }^{6} 11272947$ 
Table 1 Data of a series of 856 patients treated by lumbar wedge osteotomies for TLKD because of AS

\begin{tabular}{|c|c|c|c|c|c|}
\hline \multirow[b]{2}{*}{ Reference } & \multirow[b]{2}{*}{ Patients (n) } & \multicolumn{3}{|c|}{ Lumbar wedge osteotomies } & \multirow[b]{2}{*}{ Mortality } \\
\hline & & $\begin{array}{l}\text { Open wedge } \\
\text { osteotomies }\end{array}$ & $\begin{array}{l}\text { Polysegmental wedge } \\
\text { osteotomies }\end{array}$ & $\begin{array}{l}\text { Closing wedge } \\
\text { osteotomies }\end{array}$ & \\
\hline Bossers $^{1}$ & 4 & 4 & & & \\
\hline Bradford $^{29}$ & 8 & 8 & & & \\
\hline Briggs $^{30}$ & 5 & 5 & & & \\
\hline Camargo $^{12}$ & 66 & 66 & & & 1 \\
\hline Chapchal $^{14}$ & 2 & 2 & & & 1 \\
\hline Chen $^{2}$ & 16 & & 16 & & \\
\hline Dawson $^{7}$ & 2 & 2 & & & \\
\hline Donaldson $^{31}$ & 6 & 6 & & & 1 \\
\hline Emnéus ${ }^{15}$ & 3 & 3 & & & \\
\hline Goel $^{3}$ & 11 & 11 & & & \\
\hline $\mathrm{Halm}^{40}$ & 34 & & 34 & & 2 \\
\hline Hähnel $^{16}$ & 2 & & & 2 & \\
\hline Hehne $^{9}$ & 177 & & 177 & & 4 \\
\hline Herbert $^{32}$ & 4 & 4 & & & \\
\hline Herbert $^{33}$ & 30 & 30 & & & 4 \\
\hline Jaffray $^{17}$ & 3 & & & 3 & \\
\hline Junghanns $\mathrm{s}^{34}$ & 12 & 12 & & & \\
\hline Kallio $^{18}$ & 1 & 1 & & & \\
\hline Klems $^{19}$ & 1 & 1 & & & 1 \\
\hline La Chapelle ${ }^{20}$ & 1 & 1 & & & \\
\hline $\mathrm{Law}^{26}$ & 120 & 120 & & & 10 \\
\hline Lazennec $^{35}$ & 31 & 19 & & 12 & \\
\hline Lichtblau $^{36}$ & 5 & 5 & & & 1 \\
\hline McMaster $\mathrm{MJ}^{4}$ & 17 & 17 & & & 2 \\
\hline McMasterMJ ${ }^{11}$ & 14 & 14 & & & \\
\hline McMasterPE $^{37}$ & 15 & 15 & & & 1 \\
\hline Schubert $^{21}$ & 2 & 2 & & & \\
\hline Scudese ${ }^{22}$ & 1 & & & 1 & \\
\hline Simmons ${ }^{5}$ & 19 & 19 & & & \\
\hline Smith-Petersen ${ }^{10}$ & 6 & 6 & & & \\
\hline Stuart $^{23}$ & 1 & 1 & & & \\
\hline Styblo $^{38}$ & 20 & 20 & & & \\
\hline Thiranont ${ }^{46}$ & 6 & & & 6 & \\
\hline Thomasen $^{45}$ & 11 & & & 11 & \\
\hline Thompson $^{39}$ & 5 & 5 & & & \\
\hline Van Royen $^{13}$ & 22 & & & 22 & \\
\hline Van Royen ${ }^{62}$ & 21 & & 21 & & \\
\hline Weale $^{27}$ & 50 & 50 & & & 2 \\
\hline Weatherley ${ }^{24}$ & 2 & 2 & & & 2 \\
\hline Wilson $^{25}$ & 1 & & 1 & & \\
\hline Ziwjan $^{28}$ & 99 & & & 99 & 2 \\
\hline Total & 856 & 450 & 249 & 156 & 34 \\
\hline
\end{tabular}

In an attempt to offer a rationale for decision making on the surgical technique for correction of TLKD because of AS that yields the best results, a structured review of the literature was performed.

For the purpose of this review, the operative technique of an anterior opening wedge osteotomy according to Smith-Petersen is referred to as open wedge osteotomy (OWO) (fig 1). The technique of polysegmental lumbar posterior wedge osteotomies is referred to as polysegmental wedge osteotomies (PWO) (fig 2 ), and the monosegmental posterior closing wedge osteotomy is referred to as closing wedge osteotomy (CWO) (fig 3).

Table 2 Demographic data of series with more than 10 patients

\begin{tabular}{|c|c|c|c|c|}
\hline Reference & Patients (n) & Mean age (range) & Male & Female \\
\hline Camargo $^{12}$ & 66 & $34\left(19^{-} 55\right)$ & 59 & 7 \\
\hline $\mathrm{Chen}^{2}$ & 16 & $40\left(24^{-} 63\right)$ & 14 & 2 \\
\hline Goel $^{3}$ & 11 & $33(23-46)$ & 10 & 1 \\
\hline $\mathrm{Halm}^{40}$ & 34 & $41\left(24^{-57}\right)$ & 31 & 3 \\
\hline Hehne $^{9}$ & 177 & $41(24-65)$ & 156 & 21 \\
\hline Lazennec $^{35}$ & 31 & $44\left(32^{-}-61\right)$ & 26 & 5 \\
\hline McMaster $\mathrm{MJ}^{4}$ & 17 & $42\left(31^{-}-49\right)$ & 11 & 6 \\
\hline McMasterMJ $^{11}$ & 14 & $42\left(31^{-}-66\right)$ & 11 & 3 \\
\hline Styblo $^{38}$ & 20 & $41\left(19^{-57)}\right.$ & 19 & 1 \\
\hline Thomasen $^{45}$ & 11 & $38\left(28^{-56}\right)$ & 8 & 3 \\
\hline Van Royen ${ }^{13}$ & 22 & $48\left(27^{-}-70\right)$ & 18 & 4 \\
\hline Van Royen ${ }^{62}$ & 21 & $42\left(19^{-} 61\right)$ & 16 & 5 \\
\hline Weale $^{27}$ & 50 & $43\left(26^{-}-57\right)$ & 44 & 6 \\
\hline Ziwjan $^{28}$ & 99 & $41\left(21^{-} 56\right)$ & 97 & 2 \\
\hline Combined data & 589 & $41(19-70)$ & 520 & 69 \\
\hline
\end{tabular}

\section{Aim of the study}

The aim of this study is twofold. Firstly, to assess the quality of all reported articles concerning lumbar osteotomy for correction of TLKD resulting from AS. Special emphasis was put on three surgical techniques: OWO, PWO, and CWO. Secondly, to compare the outcomes of these three surgical techniques to determine if either one technique is preferable to another.

\section{Methods}

A comprehensive search was performed for all journal articles (referred to as reports) written in English, French, and German, published between 1966 and 1998 and referenced on Medline, concerning lumbar osteotomies for correction of TLKD because of AS. The reference lists of all publications were scanned also to find additional reports. From different reports with an overlap in the patient groups (that is, same patients described in both reports) only the report with most detailed data was used. From each report, only the data of patients with TLKD attributable to AS treated by a correction of the lumbar spine were analysed. Reports with at least 10 patients and sufficient clinical information were analysed for demographic data. After a preliminary review of all reports, a list of six data categories was developed, considered by us as the minimum 
Table 3 Technical outcome grading criteria

\begin{tabular}{ll}
\hline Good & $\begin{array}{l}\text { fusion and consolidation } \\
\text { loss of correction up to } 10^{\circ} \\
\text { no implant failure } \\
\text { pseudarthrosis or loss of correction }>10^{\circ}\end{array}$ \\
neuropraxia, deep infection, or re-operation \\
implant failure \\
no correction achieved, recurrent deformation \\
paralysis, vascular complications or fatal complications
\end{tabular}

requirements for meaningful data interpretation. These categories are: (1) at least four patients treated by the same method, (2) age and sex of patients, (3) level of the surgical procedure, (4) radiographic degrees of correction, (5) complications, and (6) subjective (patient reported) outcomes. Only reports where it was possible to analyse these six data categories were included for further analysis. The reports were further divided in three groups according to the surgical techniques used (that is, OWO, PWO, and CWO). From the reports, the degree of postoperative correction, degree of correction at follow up, loss of correction, superficial infection, deep infection, re-operation, pseudarthrosis, neuropraxia, retrograde ejaculation, paralysis, and implant failure were recorded and referred to as the technical outcome data. To allow comparison of the technical outcome data of the three surgical techniques, the results were graded good, fair, and poor according to table 3 .

\section{Results}

SEARCH OF THE LITERATURE

An extensive search of the literature revealed 59 citations. Of these, 41 reports could be included for further analysis (table 1). The reasons for exclusion of 18 reports were overlap of patient groups ${ }^{41-44} 48-52$ and absence of clinical results. ${ }^{6}{ }^{53-59}$ One author (Halm et al) reported functional outcome analysis using a subjective score. ${ }^{40}{ }^{41}$ The technical outcome data of these patients were described in more detail referred textbook. ${ }^{60}$ In another report, the results of two surgical methods were presented. $^{35}$ Because of insufficient clinical data in most of the reports, statistical analysis of the technical outcomes of the three surgical techniques was not feasible.

PATIENT SERIES AND TREATMENT GROUPS

The 41 reports describe 856 patients treated by lumbar osteotomy for TLKD resulting from AS, the data are presented in table 1 . In 450 patients $(53 \% ; 29$ studies) an OWO was performed. A PWO, reported in five studies, was performed in 249 patients (29\%). In eight studies, 156 patients $(18 \%)$ were treated by CWO. Fourteen reports including 589 (69\%) patients, met the criteria for demographic analysis. The mean age at the time of operation was 41 (range 19-73) years. The male-female ratio was 7.5 to 1 (table 2 ). Sixteen reports, including 523 patients (61\%), were analysed

Table 4 Comparison of good versus fair and poor postoperative technical outcomes for the open wedge osteotomy for reports fulfilling the inclusion criteria. The mean postoperative correction, correction at follow up, and the loss of correction in degrees. Range and median in parentheses

\begin{tabular}{|c|c|c|c|c|c|c|c|}
\hline Reference & $\begin{array}{l}\text { Patients } \\
\text { (n) }\end{array}$ & $\begin{array}{l}\text { Results } \\
\text { good }\end{array}$ & $\begin{array}{l}\text { Results } \\
\text { fair }\end{array}$ & $\begin{array}{l}\text { Results } \\
\text { poor }\end{array}$ & $\begin{array}{l}\text { Correction } \\
\text { postoperative }\end{array}$ & $\begin{array}{l}\text { Correction } \\
\text { follow up }\end{array}$ & Loss \\
\hline Bradford $^{29}$ & 8 & 2 & 5 & 1 & $\begin{array}{l}31 \\
(21-41 / 29.5)\end{array}$ & $\begin{array}{l}28 \\
(2-41 / 29.5)\end{array}$ & $\begin{array}{l}3.1 \\
(0-25 / 0)\end{array}$ \\
\hline Camargo $^{12}$ & 66 & 62 & 2 & 2 & $\begin{array}{l}? \\
(22-55 / ?)\end{array}$ & ? & ? \\
\hline Goel $^{3}$ & 11 & 9 & 2 & 0 & $\begin{array}{l}39 \\
(25-60 / 35)\end{array}$ & $?$ & $?$ \\
\hline Lazennec $^{35}$ & 19 & 6 & 12 & 1 & $\begin{array}{l}41 \\
(? / ?)\end{array}$ & $?$ & $?$ \\
\hline McMasterMJ ${ }^{11}$ & 14 & 13 & 1 & 0 & $\begin{array}{l}37.6 \\
(26-48 / 37.5)\end{array}$ & $\begin{array}{l}32.9 \\
(20-45 / 32.5)\end{array}$ & $\begin{array}{l}4.7 \\
(0-12 / 4.5)\end{array}$ \\
\hline McMasterMJ $^{4}$ & 17 & 12 & 2 & 3 & $\begin{array}{l}39^{\star} \\
(20-50 / 36.5)\end{array}$ & $?$ & $?$ \\
\hline Simmons $^{5}$ & 19 & 19 & 0 & 0 & $\begin{array}{l}47 \\
(30-60 / ?)\end{array}$ & $?$ & $?$ \\
\hline Styblo ${ }^{38}$ & 20 & 13 & 7 & 0 & $\begin{array}{l}44.4^{\dagger} \\
(30-60 / 42)\end{array}$ & $\begin{array}{l}39.9^{\dagger} \\
(19-55 / 40)\end{array}$ & $\begin{array}{l}4.5^{\dagger} \\
(-5-40 / 0)\end{array}$ \\
\hline Weale $^{27}$ & 50 & 28 & 19 & 3 & $\begin{array}{l}38.7 \\
(15-64 / ?)\end{array}$ & $?$ & $\begin{array}{l}4.8 \\
(0-20 / ?)\end{array}$ \\
\hline $\begin{array}{l}\text { Total } \\
\text { mean }\end{array}$ & 224 & 164 & 50 & 10 & 40.3 & 35.3 & 3.9 \\
\hline
\end{tabular}

${ }^{\star}$ Data reported in 16 patients. ${ }^{\dagger}$ unpublished data, personal communication.

Table 5 Comparison of good versus fair and poor postoperative outcomes for the polysegmental osteotomies for reports fulfilling the inclusion criteria. The mean postoperative correction, correction at follow up, and the loss of correction in degrees. Range and median in parentheses

\begin{tabular}{|c|c|c|c|c|c|c|c|}
\hline Reference & $\begin{array}{l}\text { Patients } \\
\text { (n) }\end{array}$ & $\begin{array}{l}\text { Results } \\
\text { good }\end{array}$ & $\begin{array}{l}\text { Results } \\
\text { fair }\end{array}$ & $\begin{array}{l}\text { Results } \\
\text { poor }\end{array}$ & $\begin{array}{l}\text { Correction } \\
\text { postoperative }\end{array}$ & $\begin{array}{l}\text { Correction } \\
\text { follow up }\end{array}$ & Loss \\
\hline Chen $^{2}$ & 16 & 0 & 6 & 0 & $\begin{array}{l}26.7 \\
(10-50 / 25.6)\end{array}$ & $\begin{array}{l}25.8 \\
(10-50 / 24)\end{array}$ & 0.9 \\
\hline Hehne $^{9}$ & 177 & 140 & 29 & 8 & $46^{\star}$ & $39^{\star}$ & $7^{\star}$ \\
\hline Halm $^{40}$ & $34^{\dagger}$ & 16 & 13 & 4 & $\begin{array}{l}40.4 \\
(23-67 / ?)\end{array}$ & 6.4 & 4 \\
\hline Van Royen $^{62}$ & 21 & 4 & 14 & 3 & $\begin{array}{l}35.9 \\
(0-68 / 36)\end{array}$ & 25.3 & 10.7 \\
\hline $\begin{array}{l}\text { Total } \\
\text { mean }\end{array}$ & 248 & 170 & 62 & 15 & 40.3 & 34.2 & 6.0 \\
\hline
\end{tabular}

${ }^{\star}$ Data reported in 53 patents. ${ }^{\dagger}$ No data of one patient who died after two years. 
Table 6 Comparison of good versus fair and poor postoperative outcomes for the closing wedge osteotomy for reports fulfilling the inclusion criteria. The mean postoperative correction, correction at follow $u p$, and the loss of correction in degrees. Range and median in parentheses

\begin{tabular}{llllllll}
\hline Reference & $\begin{array}{l}\text { Patients } \\
(n)\end{array}$ & $\begin{array}{l}\text { Results } \\
\text { good }\end{array}$ & $\begin{array}{l}\text { Results } \\
\text { fair }\end{array}$ & $\begin{array}{l}\text { Results } \\
\text { poor }\end{array}$ & $\begin{array}{l}\text { Correction } \\
\text { postoperative }\end{array}$ & $\begin{array}{l}\text { Correction } \\
\text { follow up }\end{array}$ & Loss \\
\hline Lazennec $^{35}$ & 12 & 6 & 6 & 0 & $\begin{array}{l}47.4 \\
(? / ?)\end{array}$ & $?$ & $?$ \\
Thiranont $^{46}$ & 6 & 6 & 0 & 0 & $\begin{array}{l}33.2 \\
(20-45 / 33.5)\end{array}$ & $?$ & $?$ \\
Thomasen $^{45}$ & 11 & 10 & 1 & 0 & $\begin{array}{l}28.3^{\star} \\
(12-50 / 20)\end{array}$ & $?$ \\
Van Royen & & & & & & $?$ \\
Total & 22 & 18 & 4 & 0 & $\begin{array}{l}35.1^{\dagger} \\
(25-54 / 34.5)\end{array}$ & 32.4 & 2.7 \\
mean & 51 & 40 & 11 & 0 & 36.5 & $?$ & $?$ \\
\hline
\end{tabular}

${ }^{\star}$ Data reported in nine patients. ${ }^{\dagger}$ Unpublished data.

for technical outcome data. Of these, nine reports (including 224 patients $(43 \%)$ ) deal with OWO, ${ }^{3-5} 111227293538$ four reports (including 248 patients $(47 \%)$ ) with PWO, ${ }^{2} 9062$ and four (including 51 patients $(10 \%)$ ) with CWO. ${ }^{13} 354546$

PREOPERATIVE, OPERATIVE, AND POSTOPERATIVE APPROACHES

Few authors describe their preoperative assessment - that is, measurement of the severity of the TLKD and the degree of correction needed to obtain an appropriate sagittal balance. $^{29476162}$ Böhm $^{48}$ designed a pair of glasses to measure the view angle in relation to the plumb line. Other authors advise the assessment of the deformity preoperatively by the chin-brow to vertical angle, ${ }^{61}{ }^{62}$ or by the C7 plumb line on a standing sagittal radiograph of the whole spine. ${ }^{29}$

General anaesthesia, and fibreoptic intubation are the most commonly used techniques during the operative procedure, however, some authors $^{5141520}$ advocated local anaesthesia. Whereas a prone position of the patient is generally advocated, Adams ${ }^{6}$ and Simmons ${ }^{5}$ described a surgical technique with the patient in a lateral decubitus position. Some authors advised an anterior release before or after the osteotomy in cases of osteoporotic bone, considerable disc calcification, and ossification of the anterior longitudinal ligament. ${ }^{5} 203233353862$ To prevent neurological complications, gradual plaster correction has been advocated in OWO $^{412}{ }^{15}$ and CWO. ${ }^{16}$ Neural monitoring ${ }^{35}$ and the use of a wake up test ${ }^{21129}$ has been reported sparsely.

In early reports no internal fixation was used. $^{136103839}$ Briggs et al (1947) $)^{30}$ were the first to use a spinal implant, the Wilson spinous process plate. Subsequently, internal wire

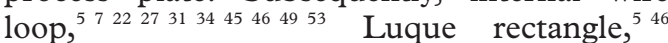
Harrington, ${ }^{11} 29384043$ and Wisconsin ${ }^{27} 38$ posterior compression instrumentation has been used. Recently, pedicle screw fixation has been used to ensure immediate stability. Some authors performed lumbar osteotomies both with and without instrumentation. ${ }^{26} 2735384561$

For postoperative treatment, all authors advocated a plaster thoracolumbar sacral orthosis (TLSO) immobilisation with one leg included. To prevent contracture of the immobilised hip joint in patients with involvement of the hips, changing the side of immobilisation of the hip after two months has been advised. ${ }^{13}$ The duration of immobilisation depended on the surgical technique, the use of internal fixation, and the postoperative stability and the quality of bone. Range from two to four months in CWO and six weeks to 15 months in OWO and PWO.

\section{MORTALITY}

Perioperative mortality was reported in $4.0 \%$ (34 of 856 patients), mostly ( $76 \% ; 26$ of 34 patients) caused by postoperative pulmonary and intestinal problems, cardiac failure, and septicaemia.

There were 26 fatal perioperative complications in OWO, six in PWO, and two in CWO. Thus the incidence of perioperative mortality in OWO was $5.8 \%$, in PWO $2.4 \%$, and in CWO $1.3 \%$ (table 1 ). Eight of 856 reported patients $(0.94 \%)$ died because of vascular complications. One patient died after a high aortic rupture because of adhesions between the aortic arch and the trachea at the level of a tracheostoma, ${ }^{12}$ another patient died after erosion of a lumbar artery related to chronic osteomyelitis, ${ }^{4}$ and one patient died of uncontrollable bleeding from small vessels. ${ }^{27}$ In one patient, a retroperitoneal haematoma caused compression of the vena cave inferior that led to a fatal Budd-Chiari syndrome. ${ }^{40}$ Fatal aortic rupture has been reported in four patients, all associated with anterior lengthening of the lumbar spine. ${ }^{192436}$ Of these, three patients were treated by OWO. ${ }^{19}{ }^{24}$ In the fourth patient, ${ }^{36}$ a fatal rupture of the aorta occurred after manipulation and non-surgical correction of a severe kyphosis in a patient who had been treated previously with roentgen treatment for AS.

\section{TECHNICAL OUTCOME DATA ANALYSIS}

The technical outcome data of 523 patients presented in 16 reports were analysed. For the overall technical outcome data, see tables 3 to 6. For a comparison of the technical outcomes of OWO, PWO, and CWO see table 7. In 330 patients, the degree of surgical correction was reported. The average postoperative correction achieved in the lumbar spine ranged from 37 to 40 degrees for the three surgical techniques. Full angular correction of the lumbar spine in PWO was not always achieved resulting in a decreased correction or monosegmental correction. $^{29} 40{ }^{62} \mathrm{Halm}^{40}$ reported in 19 of the 34 patients $(56 \%)$ a monosegmental or

Table 7 Surgical technique: comparison of the neurological complications and comparison of good versus fair and poor postoperative outcomes for the different surgical techniques of the reports fulfilling the inclusion criteria

\begin{tabular}{lllclll}
\hline Surgical technique & Reports $(n)$ & Patients $(n)$ & \% Neuropraxia & \% Paralysis & \% Results good & $\begin{array}{c}\text { \% Results } \\
\text { fair }+ \text { poor }\end{array}$ \\
\hline Opening wedge osteotomy & 9 & 224 & 8.5 & 3.1 & 73 & 27 \\
Polysegmental osteotomies & 4 & 247 & 11.3 & 2.0 & 69 & 31 \\
Closing wedge osteotomy & 4 & 51 & 7.8 & 0 & 78 & 22 \\
\hline
\end{tabular}


bisegmental correction, and Hehne and Zielke reported a monosegmental correction in $27 \%$ of their patients. Insufficient correction or no correction at all has been reported in PWO, especially in patients with osteoporotic bone and calcification of the anterior longitudinal ligament. ${ }^{62}$ Loss of correction has been reported especially in OWO and PWO, whereas, minimal loss of correction occurred in CWO (tables 4-6). In reports with loss of correction occurring in only one or two patients, this was averaged over all reported patients. ${ }^{49}$ Five authors discussed lumbar osteotomy both with and without internal fixation. ${ }^{26} 2735845$ They all observed loss of correction related to patients treated without instrumentation.

Many complications have been reported. Dura lacerations because of adhesion to the ossified ligamentum flavum in AS were frequently reported in all surgical techniques. $^{211-13153846}$ Transient nerve root dysfunction was reported equally in all surgical techniques, however, permanent neurological complications has been reported only in OWO (3.1\%; 7 of 224$)$ and PWO $(2.0 \% ; 5$ of 247$)$ (table 7 ). Transient and permanent retrograde ejaculation has been reported in seven patients in OWO. ${ }^{27}{ }^{38}$ Implant breakage and loosening of the rod-screw connection has been reported in OWO (3.6\%; 8 of 224 patients), PWO $(6.5 \% ; 16$ of 248 patients) and CWO $(3.8 \% ; 2$ of 52 patients). Screw breakout of the pedicle during correction in PWO has been reported in patients with osteoporotic bone. ${ }^{61} \mathrm{Re}-$ operations have been reported in seven patients $(3.1 \%)$ in OWO, 24 patients $(9.7 \%)$ in PWO, and three patients $(5.9 \%)$ in CWO. The indication for re-operation was neurological injury, implant failure, nonunion, deep infection, and progressive loss of correction. Deep and superficial infections reported in some reports were as high as $43 \% .^{3413273562}$

\section{Discussion}

Three operative techniques have been described to correct TLKD because of AS at the level of the lumbar spine. Which technique can be recommended? Evidence based medicine requires the choice of a surgical technique that provides the best risk to benefit ratio. Therefore, a reliable comparison of outcomes of the three techniques is necessary. However, such a comparison has not yet been reported.

The most important result to emerge from this study is, that we cannot conclude that one surgical technique is preferable over the other. This conclusion is based on the fact that there were no appreciable differences in mean postoperative correction and complication rates between the three surgical techniques. The present analysis showed that the average postoperative correction achieved in CWO was 3.8 degrees less than in OWO or PWO, however, meaningful interpretation of this difference is not feasible because of the great range of correction presented. Another reason was insufficiently reported correction at final follow up in 9 of the 16 analysed reports.

Three types of complications were associated with lumbar osteotomy for the correction of TLKD in AS: (1) loss of correction, (2) vascular complications, and (3) neurological complications. Firstly, AS related osteoporosis increases the chance of loss of correction or insufficient correction by implant loosening, implant failure, and pull-out of the laminar hooks and screw breakout of the pedicle. ${ }^{2729} 3862$ These complications have been reported in OWO and PWO especially. 32933345062 Theoretically, this may be explained by a technique related lack of primary anterior stability. In case of insufficient correction, the centre of gravity of the thorax will remain to far anteriorly of the spine. As a result, the posterior fusion zone and implants are placed under considerable tension. This increases the risk of implant failure, delayed or non-union and inevitable loss of spinal correction. Secondly, the risk of rupture of the aorta or its branches associated with the anterior lengthening of the lumbar spine in OWO is mentioned in many reports. ${ }^{1691317}$ Although this risk was shown to be small $(0.9 \%$; 4 of 450 patients), it cannot be ignored. ${ }^{19}{ }^{24} 36$ Vascular injury has been reported if the opening wedge was performed at the level L1-L2, and L2-L3. However, no vascular injury has been reported in association with procedures below level L3. Thirdly, lumbar osteotomy inevitably carries the risk of neurological complications. Displacement of a vertebral body causing a neurological deficit has been referred as a potential risk in lumbar osteotomy. ${ }^{6} 26304549$ This has been reported in six patients treated by OWO $(2.7 \%)^{35} 53$ and in one patient $(2.0 \%)$ treated by CWO. ${ }^{45}$ In these patients, no or insufficient internal fixation was mentioned as the cause of vertebral displacement.

Do the results of this study imply that there is no preference at all for one of the surgical techniques? In our opinion the answer to this question is no. Although this review showed no differences between the correction achieved by the three surgical techniques, the technical outcome data showed that with the use of CWO there is a tendency towards less serious complications. Permanent neurological complications were not reported in CWO. Furthermore, loss of correction was minimal, most probably because of the two cancellous surfaces of the vertebral osteotomy ensuring a rapid consolidation after closure. However, the maximum correction achieved with this technique is restricted by the anatomical limitations of one vertebral body. This showed to be about 35 degrees (15 to 54 degrees) (see fig 3). Interestingly, some authors ${ }^{35}$ report a correction as high as 75 degrees in CWO. The only way to explain such a correction by CWO, is by fracturing of the anterior hinge of the osteotomy, thus transforming it into OWO. In these instances, additional benefit may be obtained from pedicle screw fixation, as this will lock the corrected position like a tension band. ${ }^{17}$

Another important result of this study is, that the indications for operative treatment were generally poor defined. Preoperative clinical or radiographic assessment of the kyphotic deformity was mentioned in few (5 of 41) reports ${ }^{13} 29384862$ and one referred textbook. ${ }^{61}$ 
This is not surprising, as there are no standardised parameters for the preoperative and postoperative evaluation of the severity of TLKD attributable to AS. Different authors suggest different parameters. Assessment of the chin-brow to vertical angle ${ }^{6162}$ is easy to use, however, its reproducibility and reliability are not known. Another method is the assessment of TLKD on a standing lateral radiograph of the whole spine..$^{29}$ On these radiographs, measurements of the horizontal distance from S1 to the sagittal vertical axis or the $\mathrm{C} 7$ plumb line are suggested. These measurements, however, are found to differ depending on small changes of the angles of the hip, knee, and ankle joints and therefore are not accurate..$^{63}$ Furthermore, the exact position of the landmarks $\mathrm{C} 7$ and $\mathrm{S} 1$, and the position of the long cassette film to the horizon are not known as well.

One recent report ${ }^{35}$ presented patients treated by OWO and CWO. However, the authors did not compare the results of these two techniques. It can be questioned why there are no studies available comparing different techniques of lumbar osteotomy in AS. The explanation is twofold. Firstly, the number of patients treated by lumbar osteotomy for TLKD because of AS is low and decreasing, most probably because of successful conservative treatment. Our study showed that reports on lumbar osteotomy are sparse indeed, and that only few authors have experience with a larger number of patients. Secondly, there are no standardised methods for assessing the sagittal deformity of the spine, and accurate preoperative planning including the degree of correction required and the level to operate on. As a result investigators simply lack adequate data to perform a reliable comparative study.

Functional outcome analysis and measuring quality of life is important in surgery for TLKD because of AS. Only one author (Halm et al) reported functional outcome data in PWO using a retrospective questionnaire concerning patients treated in the 1970 s and 1980s. ${ }^{40}{ }^{41}$ All other reports focus on operative technique, degree of correction, and complication rate. Ideally, a study should evaluate the outcome of the operative procedure on the effect it procedures on the patients quality of life. However, workable methods to assess quality of life in patients with AS have only be developed recently. ${ }^{64} 65$

Specific items of the present review might be subject to criticism. A first concern is the method used to search the literature. The choice only to use reports written in English, French or German could have resulted in missing data influencing the results. Nevertheless, it is generally accepted to review reports written in English, French or German. A second concern is data analysis for selection of reports. For the purpose of this review, six data categories were considered to be a prerequisite for meaningful data analysis. The interpretation of a data category was considered satisfactory if an issue was at least mentioned. For example, Camargo et $a l^{12}$ reported of the correction of TLKD achieved in the lumbar spine varying from 22 to 55 degrees in 66 patients treated by OWO. However, the mean correction was not mentioned, and loss of correction was mentioned without further quantification. Excluding such reports would have decreased the number of reports for analysis unacceptably. Obviously, statistical analysis of the results from the three surgical treatment techniques could not be performed. This justified our use of a structured review to evaluate the technical outcome of the three surgical techniques.

\section{Conclusions}

This structured review of the literature concerning three methods of lumbar osteotomy for correction of TLKD atrributable to AS showed that reports are limited and provide scant information on clinical data. Statistical analysis of the technical outcome data from these surgical methods was therefore not possible. Although the available data from the current literature suggest that CWO causes less serious complications and has better results, these data are not suitable for decision making with regard to which surgical treatment is preferable. Furthermore, there is a need for a generally accepted clinical score that encompasses accurate measurements needed for preoperative and postoperative assessment of the spinal deformity in these patients.

1 Bossers GThM. Columnotomy in severe Bechterew kyphosis. Acta Orthop Belg 1972;38:47-54.

2 Chen PQ. Correction of kyphotic deformity in ankylosing spondylitis using multiple spinal osteotomy and Zielke's spondylitis using multiple spinal osteotomy and Zielke's
VDS instruments. J Formos Med Assoc 1988;87:692-8.

3 Goel MK. Vertebral osteotomy for correction of fixed flexion deformity of the spine. J Bone Joint Surg Am 1968; 50-A:287-94.

4 McMaster MJ, Coventry MB. Spinal osteotomy in ankylosing spondylitis: technique, complications, and long-term results. Mayo Clin Proc 1973;48:476-87.

5 Simmons EH. Kyphotic deformity of the spine in ankylosing spondylitis. Clin Orthop 1977;128:65-77.

6 Adams JC. Technique, dangers and safeguards in osteotomy of the spine. J Bone Joint Surg Br 1952;34-B:226-32.

7 Dawson CW. Posterior elementectomy in ankylosing arthritis of the spine. Clin Orthop 1957;10:274-81.

8 Gerscovich EO, Greenspan A, Montesano PX. Treatment of kyphotic deformity in ankylosing spondylitis. Orthopedics 1994; 17:335-42

9 Hehne HJ, Zielke K, Böhm H. Polysegmental lumbar osteotomies and transpedicled fixation for correction of otomies and transpedicled fixation for correction of
long-curved kyphotic deformities in ankylosing spondylitis. Report on 177 cases. Clin Orthop 1990;258:49-55.

10 Smith-Petersen MN, Larson CB, Aufranc OE. Osteotomy of the spine for correction of flexion deformity in reumatoid arthritis. J Bone Joint Surg 1945;27:1-11.

11 McMaster MJ. A technique for lumbar spinal osteotomy in ankylosing spondylitis. J Bone Joint Surg Br 1985;67-B: 204-10.

12 Camargo FP, Cordeiro EN, Napoli MM. Corrective osteotomy of the spine in ankylosing spondylitis. Experience with 66 cases. Clin Orthop 1986;208:157-67.

13 Van Royen BJ, Slot GH. Closing-wedge posterior osteotomy for ankylosing spondylitis. Partial corporectomy and transpedicular fixation in 22 cases. J Bone Joint Surg Br 1995; 77-B:117-21.

14 Chapchal G. Operative treatment of severe kyphosis as the result of Bechterew's disease. Arch Chir Neerlandicum $1949 ; 1: 57-63$

15 Emnéus H. Wedge osteotomy of spine in ankylosing spondylitis. Acta Orthop Scand 1968;39:321-6.

16 Hähnel H. Erste Erfahrungen mit operativen Kyphosekorrekturen bei M. Bechterew und M. Scheuermann. Beit Orthop Traumatol 1988;35:153-60.

17 Jaffray D, Becker V, Eisenstein S. Closing wedge osteotomy with transpedicular fixation in ankylosing spondylitis. Clin Orthop 1992;279:122-6.

18 Kallio KE. Osteotomy of the spine in ankylosing spondylitis. Ann Chir Gynaecol Fenn 1963;52:615-19.

19 Klems VH, Friedebold G. Ruptur der Aorta abdominalis nach Aufrichtungsoperation bei Spondylitis ankylopoetica. Z Orthop 1971;108:554-63.

$20 \mathrm{La}$ Chapelle EH. Osteotomy of the lumbar spine for correction of kyphosis in a case of ankylosing spondylarthritis. J Bone Joint Surg 1946;28:851-8. 
21 Schubert T. Polak K. Ergebnisse der operativen Behandlung von Patienten mit Spondylarthritis ankylopoetica. Beit Orthop Traumatol 1988;5:290-5.

22 Scudese VA, Calabro JJ. Vertebral wedge osteotomy. Correction of rheumatoid (ankylosing) spondylitis. JAMA 1963;186:627-31.

23 Stuart FW, Rose GK. Ankylosing spondylitis treated by osteotomy of the spine. BMJ 1950;1:165-6.

24 Weatherley C, Jaffray D, Terry A. Vascular complications associated with osteotomy in ankylosing spondylitis: report of two cases. Spine 1988;13:43-6.

25 Wilson MJ, Turkell JH. Multiple spinal wedge osteotomy. Its use in a case of Marie Strümpell spondylitis. Am J Surg use in a case of

26 Law WA. Osteotomy of the spine. Clin Orthop 1969;66: 70-6.

27 Weale AK, Marsh CH, Yeoman PM. Secure fixation of lumbar osteotomy. Surgical experience with 50 patients. Clin Orthop 1995;321:216-22.

28 Ziwjan JL. Die behandlung der Flexionsdeformitäten der Wirbelsäule bei der Bechterewschen Erkrankung. Beitr Orthop Traumatol 1982;29:195-9.

29 Bradford DS, Schumacher WL, Lonstein JE, Winter RB. Ankylosing spondylitis: experience in surgical managemen of 21 patients. Spine 1987;2:238-43. Erratum: Spine 1987; 12:590-92.

30 Briggs H. Keats S. Schlesinger PT. Wedge osteotomy of the spine with bilateral, intervertebral foraminotomy: correction of flexion deformity in five cases of ankylosing arthritis tion of flexion deformity in five cases of ankylosin Joint Surg 1947;29:1075-82.

31 Donaldson JR. Osteotomy of the spine for kyphus due to Donaldson JR. Osteotomy of the spine for kyphus due to

32 Herbert JJ. Vertebral osteotomy, technique, indications and results. J Bone Joint Surg Am 1948;30-A:680-9.

33 Herbert JJ. Vertebral osteotomy for kyphosis, especially in Marie-Strumpell Arthritis. J Bone Joint Surg Am 1959;41 A:291-302.

34 Junghanns H. Operative rehabilitation bei spondylitis ankylopoetica. Therapiewoche 1971;24:1835-8.

35 Lazennec JY, Saillant G, Saidi K, Arafati N, Barabas D, Benazet JP, et al. Surgery of deformities in ankylosing spondylitis: our experience of lumbar osteotomies in 31 patients. Eur Spine J 1997;6:222-32.

36 Lichtblau PO, Wilson PhD. Possible mechanism of aorta rupture in orthopaedic correction of rheumatoid spondylitis. J Bone Joint Surg Am 1956;38-A:123-7.

37 McMaster PE. Osteotomy of the spine for fixed flexion deformity. J Bone Joint Surg Am 1962;44-A:1207-16.

38 Styblo K, Bossers GT, Slot GH. Osteotomy for kyphosis in ankylosing spondylitis. Acta Orthop Scand 1985;56:294-7.

39 Thompson WAL, Ingersoll RE. Osteotomy for correction of deformity in Marie-Strumpell arthritis. Surg Gynecol Obstet 1950;90:552-6.

40 Halm H. Metz-Stevenhagen P. Schmidtt A, Zielke K Operatieve Behandlung kyphotischer Wirbelsäulendeformitäten bei der Spondylitis ankylosans mit dem HarringtonKompressionssystem: Langzeitergebnisse auf der Basis der MOPO-Skalen im Rahmen einer retrospektiven Fragenbogenerhebung. Z Orthop 1995;133:141-7.

41 Halm H, Metz-Stevenhagen P, Zielke K. Results of surgical correction of kyphotic deformities of the spine in ankylos列 ing spondylitis on the basis of the modified arthr

42 Hehne HJ, Becker HJ, Zielke K. Die Spondylodiszitis bei kyphotischer Deformität der Spondylitis ankylosans und kyphotischer Deformität der Spondylitis ankylosans und Bhre Ausheilung durch dorsale Korrekturosteotomien. Bericht über 33 Patienten. Z Orthop 1990;128:494-502.
Püschel J. Zielke K. Korrekturoperation bei Bechterew-

43 Püschel J. Zielke K. Korrekturoperation bei BechterewKyphose. Indik
120:338-42.
44 Zielke K, Rodegerds U. Operative Behandlung der fixierten Kyphose bei "Spondylitis ankylosans". Indikation, Komplikationen und Ergebnisse. Vorläufiger Bericht über 78 Fälle. Z Orthop 1985;123:679-82.

45 Thomasen E. Vertebral osteotomy for correction of kyphosi in ankylosing spondylitis. Clin Orthop 1985;194:142-52.

46 Thiranont N, Netrawichien P. Transpedicular decancellation closed wedge vertebral osteotomy for treatment of fixed flexion deformity of spine in ankylosing spondylitis. Spine 1993;18:2517-22.

47 Simmons EH. Relation of vascular complication to the level of lumbar extension osteotomy in ankylosing spondylitis. 61 st Annual meeting of the American Academy of Orthopedic Surgeons. New Orleans: 1994.

$48 \mathrm{Böhm} \mathrm{H,} \mathrm{Hehne} \mathrm{HJ,} \mathrm{Zielke} \mathrm{K.} \mathrm{Die} \mathrm{Korrektur} \mathrm{der}$ Bechterew-Kyphose. Orthopade 1989;18:142-54.

49 Law WA. Lumbar spine osteotomy. J Bone Joint Surg Br 1959;41-B:270-8.

50 Law WA. Osteotomy of the spine. J Bone Joint Surg Am 1962;44-A:1199-206.

51 Püschel J. Korrekturosteotomien beim M. BechterewKyphose. Technik, Ergebnisse. Z Orthop 1981;119:823-4

52 Roy-Camille R, Henry P, Saillant G, Doursounian L. Chirurgie des grandes cyphoses vertebrales de la spondylarthrite ankylosante. Revue du Rhumatisme et des Maladies Osteo-Articulaires 1987;54:261-7.

53 Chapchal G. Columnotomy in severe Bechterew kyphosis. Acta Orthop Belg 1972;38:55-58.

54 Dahmen G. Operative Behandlung der Bechterewschen Erkrankung. Med Monatsschr 1972;26:194-201.

55 Junghanns H. Aufrichtungsoperation bei Spondylitis ankylopoetica (Bechterew). Dtsch Med Wochenschr 1968;93: 1592-4.

56 Junghanns H. Operative Behandlung schwerer Kyphosen und Hüftarthrosen bei ankylosierender Spondylitis. Verh Dtsch Ges Rheumatol 1969;1:171-8.

57 Law WA. Surgical treatment of the rheumatic diseases. J Bone Joint Surg Br 1952;34-B:215-25.

58 Law WA. President's address. Ankylosing spondylitis and spinal osteotomy. Proceedings of the Royal Society of Medicine 1976;69:715-20.

59 Morscher E, Müller W. Operative Korrektur fixierter Kyphosen. Orthopäde 1973;2:193-200.

60 Hehne HJ, Zielke K. Die Kyphotische Deformität bei Spondylitis ankylosans. Klinik, Radiologie und Therapie. In: Sculitz KP, ed. Die Wirbelsäule in Forschung und Praxis. Stuttgart: Hippocrates Verlag, Band 1990:112:32-69.

61 Simmons EH. Ankylosing spondylitis: Surgical considerations. In: Rothman RH, Simeone FA, eds. The spine. Vol 2. 3rd ed. Philadelphia: WB Saunders 1992;1447-511.

62 Van Royen BJ, De Kleuver M, Slot GH. Polysegmental lumbar posterior wedge osteotomies for correction of kyphosis in ankylosing spondylitis. Eur Spine J 1998;7:104-10.

63 Van Royen BJ, Toussaint HM, Kingma I, Bot SDM, Caspers M, Harlaar J, et al. Accuracy of the sagittal vertical axis in a standing lateral radiograph as a measurement of balance in spinal deformities. Eur Spine J 1998;7:408-12

64 Abbott CA, Helliwell PS, Chamberlain MA. Functiona assessment in ankylosing spondylitis: evaluation of a new self-administered questionnaire and correlation with antropometric variables. Br J Rheumatol 1994;33:1060-6

65 Kennedy LG, JenkinsonTR, Mallorie PA, Whitelock HC, Garrett SL, Calin A. Ankylosing spondylitis: the correlation between a new metrology score and radiology. Br J Rheumatol 1995;34:767-70. 